\title{
O comportamento da renúncia fiscal oriunda dos gastos privados com atenção à saúde entre os anos 1996 e 2003
}

\author{
BERNARDO SICSÚ \\ MARIA DE FÁTIMA SILIANSKY DE ANDREAZZI \\ TÁSSIA GAZÉ HOLGUIN*
}

Tax expenditures with health care in Brazil: the behavior between the years 1996 and 2003. This article presents an economic approach trying to get the interrelations between the private expenditures on health care and the tax expenditures. It shows an overview of the family's expenses on health care confronted to the total of the same item declared to Secretaria da Receita Federal (Income Tax) that was converted into tax expenditures.

Keywords: private income; expenses on health care; tax expenditures.

Jel Classification: i18.

\section{INTRODUÇÃO}

A partir de um dos poucos consensos no campo da Economia da Saúde, que apresenta o mercado de assistência à saúde com características peculiares, deliberou-se por analisar a intervenção do Estado neste mercado. Através da concessão de benefícios, especificamente aquele oriundo da dedução dos gastos com atenção privada à saúde da renda auferida pelas famílias e pelas empresas, o setor público renuncia à arrecadação dos tributos sobre tal parcela da renda agregada. Portanto,

\footnotetext{
*Economista' Doutor em Saúde Coletiva, Pesquisador associado do Instituto de Estudos em Saúde Coletiva - IESC da UFRJ. E-mail: bsicsu@iesc.ufrj.br; Médica, Doutora em Saúde Coletiva. Professora adjunta da Faculdade de Ciências Médicas da UFRJ. Pesquisadora do Instituto de Estudos em Saúde Coletiva — IESC da UFRJ. E-mail: siliansky@iesc.ufrj.br; Economista, assistente de pesquisa do Instituto de Estudos em Saúde Coletiva - IESC da UFRJ. E-mail: tassiagh@hotmail.com. Este artigo é oriundo de pesquisa realizada com o apoio do CNPq processo 403458/2004-8 e da FAPERJ processo E261150.914/2005. Os autores agradecem a colaboração da equipe da Gerência de Pesquisa de Orçamento Familiares - POF' do IBGE e da COPAN/COPAT/SRF. Submetido: Junho 2006; Aprovado: Abril 2007.
} 
entende-se a renúncia fiscal como a parte dos tributos devida pelas pessoas físicas e pelas organizações (pessoas jurídicas) que o Estado declina arrecadar.

Esse benefício governamental tem permitido que os gastos das famílias sejam deduzidos de suas rendas tributáveis, portanto, decrescendo o valor do Imposto de Renda das Pessoas Físicas (IRPF). Os gastos das empresas com atenção à saúde (aqueles realizados pelos empregadores como benefícios aos empregados e respectivos familiares) são considerados "despesas operacionais", as quais são diminuídas do lucro tributável, reduzindo o Imposto de Renda das Pessoas Jurídicas (IRPJ) (Cf. SRF/RIR ${ }^{1 / 99}$ ).

Manuais de economia do setor público, como o de Biderman \& Arvate (2005), consideram tais renúncias "gastos tributários", devendo, portanto, ser computados na análise do conjunto de dispêndios do Estado com o setor saúde. Para Ocké Reis (2002: 25), "a rigor, o consumo de serviços de atenção à saúde continua sendo patrocinado pelo padrão de financiamento público, em especial, por meio da renúncia de arrecadação fiscal”.

$\mathrm{O}$ artigo se desenvolve a partir de uma abordagem de ordem econômica, visando estabelecer relações entre os gastos privados com atenção à saúde e a renúncia de arrecadação fiscal.

Para alcançar o objetivo proposto, o artigo apresenta um exame da totalidade dos gastos privados com atenção à saúde das famílias tendo como fonte as $\mathrm{POFs}^{2}$ de 1996 e de 2003, estabelecendo relações com os gastos declarados à Receita Federal pelas pessoas físicas e pelas pessoas jurídicas e que são deduzidos da renda tributável. É, também, apresentada a evolução dessas deduções, constantes da COPAT/SRF, ${ }^{3}$ a partir de 1998.

Após está introdução, a parte seguinte aborda os conceitos e as definições das variáveis usadas na pesquisa. A seguir, descreve-se a metodologia usada. $\mathrm{Na}$ terceira parte do artigo são apresentados os resultados das análises sobre os gastos, sobre a renda auferida (pelas famílias e pelas empresas) e sobre as deduções tributárias. Em continuidade, será apresentada uma discussão sobre o tema. Os comentários finais encerram o trabalho.

\section{CONCEITOS E DEFINIÇÕES}

\section{Gastos tributários}

Os gastos tributários devem ser computados na análise do conjunto de dispêndios do Estado (Biderman \& Arvate, 2005). Surrey (1967) usa a expressão

\footnotetext{
${ }^{1}$ Regulamento do Imposto de Renda.

${ }^{2}$ Pesquisa de Orçamento Familiar.

${ }^{3}$ Coordenadoria Geral de Política Tributária / Secretaria da Receita Federal.

${ }^{4}$ Cf. Surrey (1967) in Ministério da Fazenda, Estudos Tributários n ${ }^{\circ} 12$.
} 
"tax expenditure" para gastos tributários. Define-os como os dispositivos especiais da legislação do "imposto federal" norte-americano que permitem, através desse imposto, ao governo realizar gastos para alcançar objetivos econômicos e sociais. Para a SRF os "gastos tributários são gastos indiretos do governo realizados por intermédio do sistema tributário visando atender objetivos econômicos e sociais. São explicitados na norma que referencia o tributo, constituindo-se uma exceção ao sistema tributário de referência, reduzindo a arrecadação potencial e, conseqüentemente, aumentando a disponibilidade econômica do contribuinte. Têm caráter compensatório, quando o governo não atende adequadamente a população dos serviços de sua responsabilidade, ou têm caráter incentivador, quando o governo tem a intenção de desenvolver determinado setor ou região.” (SRF, 2003: 13).

A SRF, que é responsável pela apuração, estimativa e divulgação dos dados sobre os benefícios tributários, em 1996 "procedeu a um reexame do conceito de renúncia tributária, passando a considerar como tal somente aqueles que se enquadrem, cumulativamente, nas seguintes hipóteses" (SRF, 2002: 1).

- reduzem a arrecadação potencial;

- aumentam a disponibilidade econômica do contribuinte; e,

- constituem, sob o aspecto jurídico, uma exceção à norma que referencia o tributo ou alcançam, exclusivamente, determinado grupo de contribuintes.

A partir das hipóteses que fundamentam o conceito de "benefício tributário", estabelecidas pela SRF, é que se pretende mostrar a dinâmica da renúncia fiscal.

\section{Gastos com atenção à saúde}

No sistema brasileiro de atenção à saúde predominam duas vertentes identificadoras da natureza das despesas. A primeira é o gasto público, em que predomina o Sistema Único de Saúde - SUS. Nesta pesquisa entende-se como gasto público aquele efetuado por órgão governamental com a finalidade de atender a demandas sociais e cuja origem do financiamento é o orçamento público, como o do Ministério da Saúde - MS, o das Secretarias Estaduais e Municipais da Saúde. A segunda é o gasto privado, em que são preponderantes as famílias e as empresas. O gasto das famílias significa os dispêndios com seguro-saúde, medicamentos, consultas, hospitalização e alguns outros itens destinados à promoção e prevenção da saúde, que são efetuados pelas unidades de consumo (IBGE, 2004). Os gastos das empresas são aqueles realizados por estas unidades como benefício aos seus empregados (e dependentes) e que podem ser apresentados à legislação do imposto sobre a renda (RIR/99) como despesas operacionais, portanto, "gastos dedutíveis" da receita.

\section{Renda das famílias}

No presente artigo, a renda das famílias será aquela constante da declaração nas POFs. Especificamente, a análise recai sobre o rendimento monetário que con- 
siste em "todo e qualquer tipo de ganho monetário recebido durante o periodo de referência de 12 meses anteriores à data de realização da coleta das informações" (IBGE, 2004: 32).

\section{Receita das empresas}

Foram considerados como receita das empresas aqueles valores declarados pelas PJs na "declaração anual do imposto de renda". Assim, a base de dados da SRF/COPAT foi a fonte de informação para a análise da receita das empresas. Estas informações são oriundas do Anuário Estatístico do Imposto de Renda 2000, abrangendo todos os tipos de declarações, ou seja:

i) Lucro real PJ em geral; ii) Lucro presumido; iii) Simples; iv) Empresas imunes e isentas.

\section{METODOLOGIA}

As bases de dados utilizadas para o desenvolvimento do trabalho foram as do IBGE, representadas pelas POFs de 1996 e 2003, e as da Secretaria da Receita Federal, através dos estudos publicados pela COPAT.

Com base nas Notas Técnicas e Metodologia das POFs, constatou-se que a de 1996/1997 abrangeu um período de 12 meses, entre outubro de 1995 e setembro de 1996. O salário mínimo vigente em setembro de 1996 era de $\mathrm{R} \$ 112,00$ (Cf. Ocké Reis, 2002, e IBGE, 1997). A POF de 2002/2003 englobou o período de julho de 2002 a junho de 2003. O salário mínimo considerado foi de $\mathrm{R} \$ 200,00$. (Cf. IBGE, 2004), vigente na data referencial da pesquisa, o dia 15 de janeiro de 2003.

Para efeito de comparação dos dados das POF's de 1996 e 2003 encontrou-se alguns obstáculos de ordem econômica, metodológica e demográfica, que foram contornados com o tratamento descrito nos parágrafos subseqüentes.

Para comparar o montante da renda e dos gastos declarados pelas famílias na pesquisa do IBGE de 1996/1997 com os de 2002/2003, utilizou-se o fator 1,5875, referente ao INPC 5 acumulado entre 15 de setembro de 1996 e 15 de janeiro de 2003. De modo geral, sempre indicado nas tabelas, todos os valores monetários que necessitaram de correção foram centrados em 15 de janeiro de 2003.

Nas tabelas de despesas com assistência à saúde foram consideradas apenas as despesas monetárias. Segundo o IBGE, "são aquelas efetuadas através de pagamentos, realizados à vista ou a prazo, em dinheiro, cheque ou com utilização de cartão de crédito" (IBGE, 2004: 15).

Ocké Reis, Silveira e Andreazzi (2002:27), declaram, quando descrevem os resultados comparativos da POFs de 1987 e a de 1996, que: "A comparação dos gastos com assistência à saúde entre os anos da POF apresentou problemas de

\footnotetext{
${ }^{5}$ Índice Nacional de Preço ao Consumidor.
} 
ordem econômica, demográfica e metodológica (a distorção causada pelo item de gasto "outros")". No presente trabalho, optou-se por utilizar a agregação da POF/96, pois a POF de 2003 aumentou o escopo da investigação, por tipo de despesa, em relação à de 1996. Foram consideradas, em 2003, as despesas com serviços relativos à saúde tais como: remédios, planos e seguros saúde, consulta e tratamento dentário, consulta médica, tratamento ambulatorial (cauterização, curativo, nebulização, aplicação de raio laser, hemodiálise e outros), serviços de cirurgia, hospitalização, exames diversos (eletrodiagnóstico, exame de laboratório, radiografia, etc.), material de tratamento (seringa, termômetro, teste de gravidez, óculos e lentes, etc.). Na linha "Outras", estão agregadas as despesas e aquisições com chupeta, mamadeira, ambulância (remoção) e aluguel de aparelho médico. Na POF de 1996, o item "Outros" contemplava os seguintes produtos: anticoncepcional e hormônio; soro fisiológico hidratante; material de curativo; produtos farmacêuticos de higiene, para curativos, de puericultura, preservativos etc.; atendimento realizado por curandeiro e curioso; prótese e aparelho dentário; eletrodiagnóstico; exame de laboratório; radiografia; cauterização, curativo, nebulização, vacinação e outros tratamentos ambulatoriais; artigos ortopédicos e outros artigos médicos; aluguel de aparelho médico; outros tratamentos (psicológico, massagem etc.), enfermeira, conserto de aparelhos médicos, acompanhante, raio laser e sangue humano; fotografia relativa à cirurgia; oxigênio (despesa com saúde), exames ergométricos e audiométricos, lente intra-ocular.

Portanto, para minimizar possíveis distorções nos resultados, entre as POFs de 1996 e 2003 são passíveis de comparação os seguintes itens:
a) Remédios
b) Plano/seguro-saúde
c) Consulta/tratamento dentário
d) Consulta médica
e) Hospitalização/cirurgia

Estes itens têm maior representatividade na composição dos gastos com atenção à saúde (com cerca de $80 \%$ ).

A análise sobre a renda das famílias tem origem, também, nos dados fornecidos pela IBGE, através da análise dos microdados das POFs de 1996 e 2003. Como já citado, foram considerados apenas os rendimentos monetários, pois em 2003 a metodologia da pesquisa incluiu a categoria de "rendimentos não monetários", que não existia em 1996. Assim, para que a comparação não sofresse distorção, foi considerada apenas a classificação constante nas duas pesquisas.

Diferente da POF de 1996, a de 2003 englobou pessoas residentes na área rural, mas nesta pesquisa, para efeitos comparativos, os dados do IBGE foram filtrados. Foram considerados apenas as das áreas Metropolitanas, de modo que os dados fossem compatíveis.

Para a análise da renda (tributável) e das deduções com assistência à saúde (despesas operacionais) das empresas, a fonte de informação utilizada foi a base de dados da SRF/COPAT. A título de esclarecimento metodológico utilizou-se, 
neste artigo, o conceito de "Gasto Tributário" e "Benefício Tributário" oriundo do trabalho Estudos Tributários, número 12, denominado "Gastos Governamentais Indiretos, de Natureza Tributária - Conceituação", publicado em abril de 2003 pela equipe da COPAT/COPAN.

Cabe citar que autores como Dain, Quadros e Cavalcanti (2002), em documento editado pela Agência Nacional de Saúde Suplementar, identificam a ausência de informações mais detalhadas sobre o volume de recursos utilizados em benefícios fiscais na área da saúde. As informações desagregadas, por setor econômico e por modalidade de operação de cada instituição, permitiriam uma análise mais elaborada.

No intuito de facilitar a leitura e a interpretação dos resultados encontrados no presente artigo, são descritas a seguir, de forma sintética, as principais diferenças de abordagem com relação aos trabalhos dos autores citados:

a) $\mathrm{O}$ índice de atualização monetária foi o INPC (fator 1,5875) acumulado entre 15 de setembro de 1996 e 15 de janeiro de 2003, data referencial da POF. Entende-se que a utilização de um indicador específico para a atualização monetária do setor saúde, como por exemplo o Índice Nacional de Preços ao Consumidor Amplo (INPC-A, da Saúde e Cuidados Pessoais) ${ }^{6}$ captaria melhor a dinâmica dos preços da cesta de consumo dos itens, propiciando melhor entendimento, do ponto de vista monetário, dos gastos das famílias. Mas, no caso em questão, a utilidade seria apenas complementar. A razão da escolha da alternativa descrita acima (INPC) é referendada pela metodologia usada pelo IBGE, pois, quando do tratamento dos dados, comparou as duas pesquisas (1996 e 2003) utilizando este índice.

b) Para análise dos gastos e da renda foram utilizadas as informações da renda e das despesas monetárias, conforme já definidas em parágrafos anteriores. A justificativa é que na POF de 1996 não havia as classificações de "renda não monetária" e de "despesas não monetária”. Estas classificações só surgem na metodologia da pesquisa de 2003.

O tratamento desses dados contou com a colaboração da equipe da Gerência de Pesquisa de Orçamentos Familiares - POF do IBGE.

Ao mencionar a existência de trabalhos que seguem a mesma linha de análise, indicam-se, ao leitor, alternativas de abordagens e reflexão e, ao mesmo tempo, alerta-se que a comparabilidade dos resultados obtidos nas diversas pesquisas só tem validade se forem consideradas as questões particulares de cada metodologia.

\section{RESULTADOS}

A finalidade desta seção é apresentar os principais resultados encontrados na pesquisa e terá início pelas despesas das famílias com assistência à saúde, conforme quadro a seguir.

\footnotetext{
${ }^{6}$ Utilizado por Ocké Reis, Silveira e Andreazzi (2002).
} 
Tabela 1: Despesa monetária total anual (em milhões de Reais de 2003) com assistência à saúde, segundo os tipos de despesa.

\begin{tabular}{l|r|r|c}
\hline \multicolumn{1}{c|}{ Tipos de despesa } & \multicolumn{1}{c|}{$1996\left(^{*}\right)$} & \multicolumn{1}{c}{2003} & \multicolumn{1}{c}{ Variação (\%) } \\
\hline Total & $34.426,57$ & $23.317,13$ & $-32,27$ \\
Remédios & $9.977,07$ & $8.167,48$ & $-18,14$ \\
Plano/seguro-saúde & $9.992,25$ & $8.486,81$ & $-15,07$ \\
Consulta/tratamento dentário & $5.125,09$ & $2.832,69$ & $-44,73$ \\
Consulta médica & $1.384,65$ & 952,37 & $-31,22$ \\
Hospitalização/cirurgia & 826,99 & 734,47 & $-11,19$ \\
Outros & $6.236,62$ & $2.141,42$ & $-65,66$ \\
\hline
\end{tabular}

(*) Corrigido pelo fator 1.5875 .

Fonte: IBGE, Diretoria de Pesquisas, Coordenação de Índices de Preços, Pesquisa de Orçamentos Familiares 1995 1996/2002-2003. Elaboração Própria.

Corrigindo os valores da POF de 1996 para o dia 15 de janeiro de 2003, encontrou-se uma redução geral, sobre todos os itens de despesa, de 32,3\%.

O gráfico a seguir mostra uma redução das despesas "per capita" com assistência à saúde para a POF do ano de 2003, em relação à do ano de 1996.

Gráfico 1: Despesas com atenção à saúde, per capita por classes de rendimento. Brasil, 1996 e 2003.

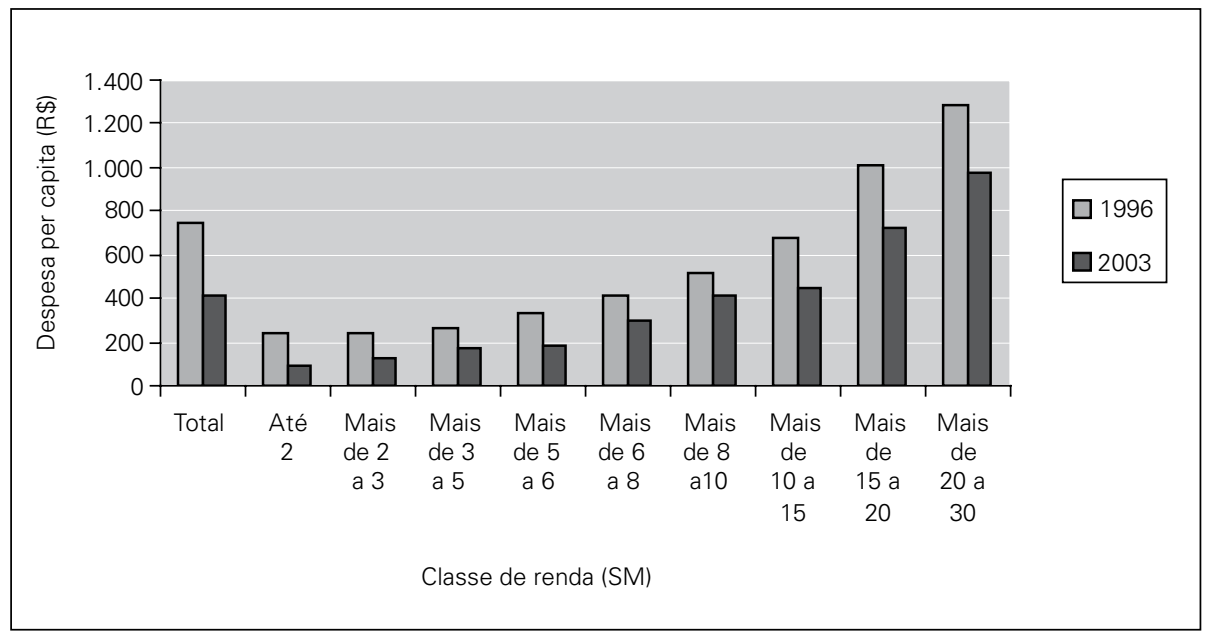

Fonte: POFs de 2003 e 1996. Elaboração própria.

O quadro a seguir mostra a participação relativa dos gastos com assistência à saúde em relação ao total dos gastos das famílias, declarados nas POFs de 1996 e 2003. Não houve variação significativa entre uma pesquisa e outra, pois a queda no total dos gastos foi de apenas meio ponto percentual. 
Tabela 2: Despesa monetária anual (em milhões de reais)

\begin{tabular}{c|c|c}
\hline Despesas das famílias & $\left.1996{ }^{*}\right)$ & 2003 \\
\hline Com assistência à saúde & $34.426,57$ & $23.317,13$ \\
\hline Despesa total & $529.281,68$ & $390.616,94$ \\
\hline $\begin{array}{l}\text { Participação \% das despesas com assistência } \\
\text { à saúde na despesa total }\end{array}$ & 6,5 & 6,0 \\
\hline
\end{tabular}

(*) Valores corrigidos pelo INPC - Fator 1,5875.

Fonte: IBGE, Diretoria de Pesquisas, Coordenação de Índices de Preços, Pesquisa de Orçamentos Familiares 1995-1996/2002-2003. Elaboração própria.

A seguir apresenta-se um quadro com as informações referentes às deduções com assistência à saúde, declaradas para a SRF, no período compreendido entre 1998 a 2003.

Tabela 3: Benefícios tributários com assistência à saúde das pessoas físicas, entre 1998 e 2003

\begin{tabular}{c|c|c|c|c|c|c}
\hline ITENS & \multicolumn{5}{|c}{ Valores em milhões de R\$ (de 2003)(**) } \\
\hline $\begin{array}{c}\text { Deduções do rendimento } \\
\text { tributável - PF }\end{array}$ & 1998 & 1999 & 2000 & 2001 & 2002 & $2003\left({ }^{*}\right)$ \\
\hline Despesas Médicas & $1.421,21$ & $1.423,78$ & $1.547,76$ & $1.449,34$ & $1.396,83$ & $1.265,57$ \\
\hline
\end{tabular}

Fonte: Copan/Copat/SRF, 2003.

$\left({ }^{*}\right)$ Valores estimados. $\left(^{* *}\right)$ Corrigidos pelo IPCA. Elaboração própria.

O total das deduções declarado pelas famílias, em termos nominais, cresceu relativamente $36,1 \%$ entre 1998 e 2003 , representando uma média anual de $5,27 \%$.

A correção dos valores, para o ano de 2003, mostra estabilidade, com tênue tendência de queda nos três últimos anos.

Por hipótese, é possível identificar que a incongruência entre a redução dos benefícios tributários com assistência à saúde e as despesas das famílias com a mesma rubrica no período pode estar relacionada com a incorporação como contribuintes das faixas até cinco salários mínimos, únicas que aumentaram seus gastos com saúde e seus rendimentos. Talvez a explicação para este fato esteja vinculada à defasagem entre os índices de correção do salário mínimo e do limite da isenção fiscal.

Após a apresentação das despesas, os parágrafos seguintes abordam os aspectos das receitas das famílias.

A renda auferida pelas famílias, declaradas nas pesquisas do IBGE para os anos em análise, encontra-se na tabela seguinte. 
Tabela 4: Renda monetária total anual (em milhões de reais de 2003) segundo as classes de rendimento monetário mensal familiar (SM)

\begin{tabular}{l|c|c|c}
\hline \multicolumn{1}{c|}{ Classes de rendimento } & $1996\left({ }^{*}\right)$ & $\mathbf{2 0 0 3}$ & Variação (\%) \\
\hline Total & $\mathbf{6 2 8 . 5 3 7 , 3 2}$ & $\mathbf{4 1 2 . 3 2 7 , 1 4}$ & $-34,40$ \\
Até 2 & $5.843,76$ & $6.945,51$ & 18,85 \\
Mais de 2 a 3 & $8.935,91$ & $10.348,43$ & 15,81 \\
Mais de 3 a 5 & $25.728,80$ & $27.958,34$ & 8,67 \\
Mais de 5 a 6 & $16.630,33$ & $12.998,37$ & $-21,84$ \\
Mais de 6 a 8 & $32.973,65$ & $27.792,15$ & $-15,71$ \\
Mais de 8 a 10 & $29.893,07$ & $23.012,68$ & $-23,02$ \\
Mais de 10 a 15 & $69.407,88$ & $49.437,58$ & $-28,77$ \\
Mais de 15 a 20 & $57.397,97$ & $38.929,40$ & $-32,18$ \\
Mais de 20 a 30 & $78.908,80$ & $60.616,04$ & $-23,18$ \\
Mais de 30 & $302.817,15$ & $154.288,65$ & $-49,05$ \\
\hline
\end{tabular}

(*) Valores corrigidos pelo fator 1,5875

Fonte: IBGE, Diretoria de Pesquisas, Coordenação de Índices de Preços, Pesquisa de Orçamentos Familiares 1995-1996/2002-2003. Elaboração Própria

Em valores correntes (dos anos das pesquisas) constata-se uma redução de $19,1 \%$ da renda das famílias que estão situadas na faixa acima de 30 salários mínimos - SM. O destaque da análise é o crescimento nominal da renda da classe que aufere até dois $\mathrm{SM} / \mathrm{mês}: 88,7 \%$. Na totalidade, a renda cresceu $4,1 \%$.

A correção dos valores da POF de 1996 para a data de 15 de janeiro de 2003 resultou numa variação negativa de $34,4 \%$ no total da renda mensal auferida pelas unidades familiares entrevistadas. A classe de rendimento acima de $30 \mathrm{SM}$ foi a que maior impacto sofreu na redução da renda $(49 \%)$.

Pode-se notar que na totalidade da renda para as classes até cinco SM ocorre uma tênue elevação no ano de 2003 e a partir desta classe há uma queda acentuada. $\mathrm{Na}$ análise do gráfico a seguir, onde a "renda per capita" é a variável exposta, constata-se um decréscimo da renda para todas as classes de rendimento. Pode-se deduzir que a elevação na totalidade da renda das famílias das classes até cinco SM ocorreu em função do acréscimo do número de pessoas agregadas na composição do rendimento. O Gráfico 2 mostra a renda "per capita”. 


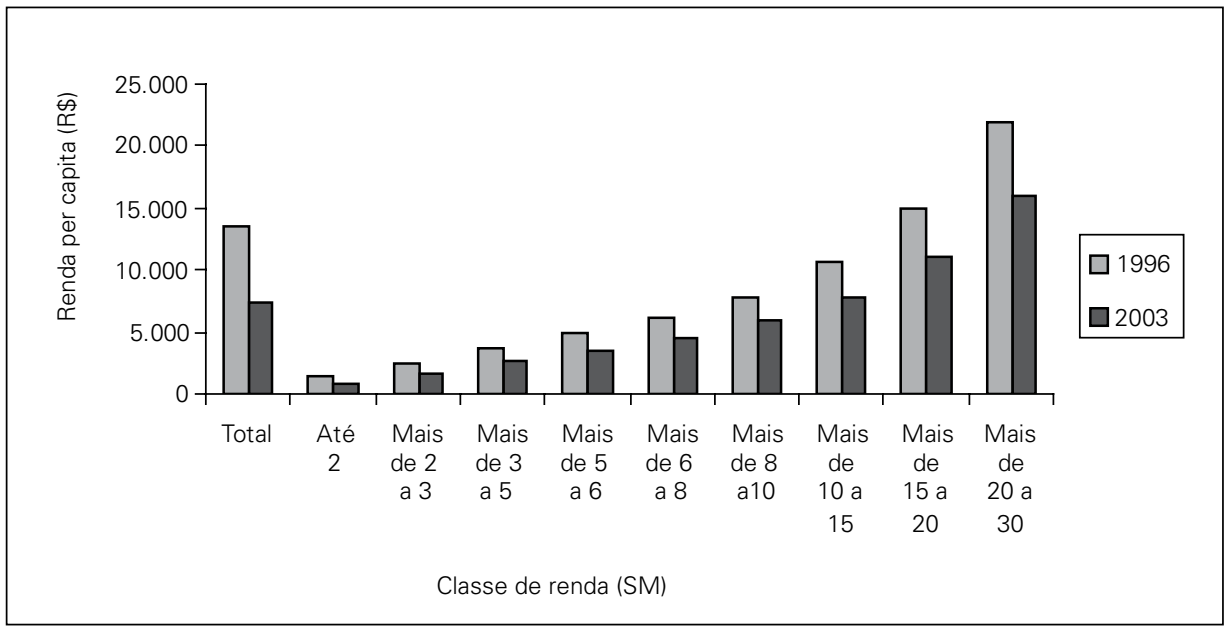

Fonte: POFs 1996 e 2003. Elaboração própria.

Os gastos das empresas com assistência à saúde dos seus empregados e de seus dependentes são considerados pela RIR/99 despesas operacionais. Portanto, são diminuídos do lucro tributável, reduzindo o imposto devido. Por este motivo foi o item escolhido para análise da pesquisa. A tabela a seguir, elaborada com os dados oriundos do COPAT/SRF, servirá de base para a descrição dos eventos.

Tabela 5: Deduções com assistência à saúde do lucro tributável das pessoas jurídicas, entre 1998 e 2003

\begin{tabular}{c|c|c|c|c|c|c}
\hline $\begin{array}{c}\text { Valores em } \\
\text { Milhões de R\$ }\end{array}$ & 1998 & 1999 & 2000 & 2001 & 2002 & 2003 \\
\hline Correntes & $2.921,94$ & $2.589,42$ & $2.448,17$ & $3.565,02$ & $3.035,26$ & $4.333,13$ \\
\hline De $2003\left(^{*}\right)$ & $4.467,42$ & $3.634,13$ & $3.242,19$ & $4.384,82$ & $3.317,54$ & $4.333,13$ \\
\hline
\end{tabular}

$(*)$ - Corrigidos pelo IPCA.

Fonte: Copan/Copat/SRF, 2005.

Elaboração própria.

Para os gastos das empresas (considerados "despesas operacionais”), em termos relativos, a evolução nominal entre 1998 e 2003 foi de 48,3\%, com média anual de crescimento de $6,8 \%$.

Em contraposição aos gastos e tendo como fonte primária dos dados o Anuário Estatístico do Imposto de Renda 2000, constata-se uma evolução positiva de $32,9 \%$, em valores nominais, entre a receita auferida pelas empresas no ano de 1998 (R\$ 1.287.621,39 milhões) e no ano 2000 (R \$ 1.711.322,04 milhões). A média de crescimento anual foi de $9,9 \%$. Em valores corrigidos pelo IPCA, constata-se um crescimento de $22,0 \%$ no período, com média de $6,8 \%$ para cada ano da série. 
Por tratar-se de um imposto direto e, por hipótese, progressivo, é importante verificar a dinâmica da tributação sobre a renda das pessoas físicas (IRPF) e sobre o lucro tributável das pessoas jurídicas (IRPJ) para financiar - em última instância - o agente econômico "famílias", cujo acesso ao consumo, pela renda, é regressivo.

As deduções com assistência à saúde concedidas às pessoas físicas e às jurídicas, quando da elaboração das declarações de ajuste anual da renda, são consideradas "benefícios tributários", portanto, alvo desta análise.

Os dados da renda anual declarada pelas famílias nas POFs de 1996 e 2003, confrontados com os gastos com assistência à saúde e as deduções com o mesmo item declaradas à SRF, estão na Tabela 6, a seguir.

Tabela 6: Renda, Gastos e Deduções com assistência à saúde. Famílias.

\begin{tabular}{l|r|r|r}
\hline \multicolumn{1}{c|}{ ITENS } & \multicolumn{1}{c|}{$1996\left(^{*}\right)$} & \multicolumn{1}{c}{2003} & \multicolumn{1}{c}{ Var \% } \\
\hline Renda anual & $628.537,32$ & $412.327,14$ & \multicolumn{1}{c}{$-34,40$} \\
Gastos com assistência à saúde & $34.426,57$ & $23.317,13$ & $-32,27$ \\
Deduções com assistência à saúde & $9.295,30$ & $18.009,41$ & 93,74 \\
Arrecadação IRPF & $21.217,26$ & $31.560,0$ & \multicolumn{1}{c}{48,75} \\
\hline
\end{tabular}

(*) Valores em Milhões de $\mathrm{R} \$$ corrigidos pelo fator 1,5875.

Fonte: POF's 1996/2003 e SRF/COPAT.

Elaboração própria.

Centrados na mesma base, os números permitem observar uma grande retração da renda das famílias (34,4\%) entre o ano de 1996 e o de 2003. Esta redução ocorre também para o total dos gastos com assistência à saúde em $32,3 \%$, em que a análise por tipo de despesa indica que a maior queda - 44,7\% - foi no gasto foi com o item "Consulta e tratamento dentário". A análise sobre o item "Outros", que apresentou $65,6 \%$ de redução, não é relevante, em função de agregações metodológicas, portanto, passível de interpretações equivocadas.

Em paradoxo com a redução da renda e dos gastos das famílias, constata-se que as deduções com assistência à saúde, declaradas à SRF, evoluíram, positivamente, $93,7 \%$. Isto pode ser um indicativo de que as famílias buscaram abrigo nos benefícios fiscais para minimizar a retração da sua renda. Nota-se, também, o acréscimo, em 28,9\%, da arrecadação proveniente do IRPF, apesar do incentivo fiscal ter quase dobrado no período.

Para análise das informações sobre as organizações (pessoas jurídicas) recorreu-se aos quadros a seguir, obtidos na base de dados da SRF. 
Tabela 7: Receita e deduções com assistência médica (pessoas jurídicas)

\begin{tabular}{c|c|c|c|c}
\hline Anos & Receita & Evolução \% & Deduções & Evolução \% \\
\hline 1998 & $1.287 .621,39$ & - & $2.921,94$ & - \\
1999 & $1.339 .785,19$ & 4,05 & $2.589,42$ & $-11,38$ \\
2000 & $1.711 .322,04$ & 27,7 & $2.448,17$ & $-5,45$ \\
\hline
\end{tabular}

Valores em milhões de $\mathrm{R} \$$ (correntes).

Fonte: Anuário Estatístico do Imposto de Renda 2000 e Copan/Copat/SRF, 2005.

Elaboração própria.

$\mathrm{Na}$ falta de dados mais atuais, a análise incide sobre a dinâmica da receita e das deduções entre 1998 e 2000 . Constata-se que a receita no período teve uma evolução de $32,9 \%$, enquanto as despesas operacionais, representadas pelas deduções, tiveram um movimento regressivo acumulado de $(-17,5 \%)$. Verifica-se que a participação das deduções na receita das PJs é ínfima e decrescente, representando 0,20\% em 1998, 0,19\% em 1999 e 0,14\% em 2000.

Em se tratando do imposto total sobre a renda, a arrecadação total administrada pela SRF, constatou-se uma evolução de 23,1\% entre os anos de 1998 e 2002. A arrecadação sobre a renda das pessoas físicas (IRPF) teve um acréscimo de $20,7 \%$, e sobre renda das empresas (IRPJ) foi de $41,2 \%$. Com base nestes números, há evidência que mesmo com o uso, pela PFs e pelas PJs, das deduções das despesas com assistência à saúde, não houve decréscimo no montante dos valores correntes arrecadados pelo Estado.

A conjugação dos resultados das três últimas tabelas apresentadas permite afirmar que para as PJs a utilização do benefício fiscal foi decrescente, pois enquanto houve queda na dedução dos gastos $(-17,5 \%)$, houve um incremento na arrecadação $(41,2 \%)$. Para as PFs (no período compreendido entre as POFs de 1996 e 2003) o resultado foi inverso: houve um avanço no uso do benefício, pois o valor da utilização (em termos reais) quase dobrou, enquanto o da arrecadação cresceu (em valores corrigidos) $28,9 \%$.

Tabela 8: Benefícios tributários das despesas com assistência à saúde — em milhões de 2003

\begin{tabular}{c|c|c|c|c|c|c}
\hline Classes & 1998 & 1999 & 2000 & 2001 & 2002 & 2003 \\
\hline PFs $\left(^{*}\right)$ & $1.421,21$ & $1.423,78$ & $1.547,76$ & $1.449,34$ & $1.396,83$ & $1.265,57$ \\
\hline PJs & 695,79 & 616,60 & 582,98 & 848,92 & 722,77 & 649,97 \\
\hline TOTAL & $2.117,00$ & $2.040,38$ & $2.130,74$ & $2.298,26$ & $2.119,60$ & $1.915,54$ \\
\hline
\end{tabular}

(*) Valores estimados.

Fonte: Para as PFs, SRF/Benefícios tributários por modalidade. Para as PJs SRF/Copan.

Elaboração própria.

$\mathrm{Na}$ ótica de análise da SRF, os números do quadro acima são considerados benefícios tributários, pois reduzem a arrecadação potencial e aumentam a disponibilidade econômica do contribuinte. 
Pode-se observar que o incremento absoluto dos valores é de pequena monta, não influenciando, relativamente, o total da arrecadação.

Resumindo os resultados da pesquisa tem-se que as famílias reduziram (em termos reais) os gastos com assistência à saúde no orçamento familiar e procuraram compensar as perdas reais na renda auferida utilizando o benefício fiscal da dedução dessas despesas na declaração de ajuste anual do imposto sobre a renda. No caso das PJs, por falta de informações mais detalhadas, não foi possível identificar, com clareza, a tendência do movimento, embora entre os anos de 1998 e 2003 constata-se uma suave redução do gasto tributário.

Quanto ao comportamento da arrecadação, o que se apurou foi um firme e progressivo incremento, quer seja de modo relativo ou de modo absoluto.

\section{DISCUSSÃO}

Nesta seção são comentados os resultados encontrados na pesquisa e foram feitas algumas observações que permitam ao leitor formar um juízo de valor sobre o tema. Além disso, incentivar um colóquio com outros trabalhos da mesma natureza, colaborando para melhor entendimento da questão.

Como referência histórica e de forma sintética, convém mostrar, nos parágrafos iniciais desta seção, os principais resultados encontrados por Ocké Reis, Silveira e Andreazzi (2002) em análise das POFs 1987 e 1996, com relação aos gastos das famílias com assistência à saúde. Para estes autores, no período entre as duas pesquisas, o peso do gasto com atenção à saúde no orçamento das famílias aumentou $50 \%$ para os estratos de renda inferior e intermediário. O gasto "per capita", na média, foi reduzido em torno de $30 \%$, com distribuição desigual entre os diversos estratos de renda. No estrato de $30 \mathrm{SM}$ ou mais a queda real foi significativa, atingindo $34 \%$. Outra observação foi que o gasto médio "per capita" com o item "plano de saúde", das famílias situadas no estrato de renda até dois SM, foi insignificante. Vale lembrar que, a partir de 1991, as famílias passaram a ter incentivos fiscais para o consumo dos "planos individuais" (pessoa física), embora o estrato inferior da categorização não seja onerado com a tributação sobre a renda (faixa de isentos do $\mathrm{IR}^{7}$ ). Em síntese, com relação à dinâmica dos gastos com assistência à saúde, os autores afirmam: i) houve uma redução do gasto total entre os anos da pesquisa, seguindo a redução do gasto per capita; ii) as maiores reduções ocorreram nos estratos situados no topo da distribuição da renda; iii) os gastos estavam concentrados principalmente na região Sudeste; iv) ocorreu um aumento expressivo do gasto total com planos de saúde simultaneamente à redução das despesas com serviços médico-hospitalares. Esse aumento foi de $74 \%$ e o valor do gasto alcançou R $\$ 4$ bilhões em 1996, o que representou $30 \%$ do total com assistência à saúde; v) do ponto de vista dos gastos com assistência à saúde,

\footnotetext{
${ }^{7}$ Para a declaração de 2006, ano-base 2005, o valor de isenção é de R\$13.968,00/ano.
} 
dos estratos inferiores da renda, fica notória a compulsoriedade de tais gastos, tratando-se de um serviço essencial da população.

$\mathrm{Na}$ atual pesquisa, em termos gerais, os números mostram uma redução da renda auferida pelas famílias entre 1996 e 2003. Esta queda no rendimento repercutiu nos gastos das famílias, de modo geral e, especificamente, no gastos com assistência à saúde, em que o item "Consulta/tratamento dentário" foi o mais afetado. A análise dos dados não permitiu encontrar um indicador consistente para tal fenômeno, embora trabalhos similares, respeitando suas peculiares estratégias metodológicas, alcancem indicativos bastante próximos. Ocké Reis (2002) desenvolveu uma pesquisa analisando e interpretando os dados das POFs de 1987 e 1996, em que foram identificadas as estruturas de gasto, de receita e de poupança das famílias. A ênfase foi para a avaliação do gasto com seguro-saúde e "associação de assistência", isto é, com "planos de saúde", dando especial atenção aos resultados encontrados para os estratos de "renda inferior" e "renda intermediária". Faz-se indispensável, também, citar os trabalhos analíticos sobre os gastos com assistência à saúde de autores como Silveira, Osório e Piola (2002), utilizando as versões das POFs de 1987 e 1996, e o de Almeida (1998), sobre o mesmo tema, a partir da base de dados da SRF/IRPF, ano-base de 1996.

Quanto às pessoas jurídicas encontrou-se um incremento nominal de 32,9\% na receitas entre o período de 1998 e 2000 (período utilizado para análise conforme descrito na metodologia), enquanto as deduções das despesas, também em termos nominais, regrediram em torno de $17,5 \%$. Observou-se ainda que a participação desta rubrica com relação à receita das empresas é ínfima e está num processo decrescente entre 1998 e 2000.

$\mathrm{Na}$ questão tributária, propriamente dita, constatou-se que a arrecadação total administrada pela SRF cresceu 23,1\% no período analisado (1998/2000). Para este valor a contribuição das PFs foi de $20,7 \%$ e das PJs $41,2 \%$. A interpretação deste comportamento é que houve um esforço, por parte da SRF, para elevar os níveis da arrecadação, e, embora ocorrendo um aumento de pequena monta das deduções das PFs, isto não influenciou, relativamente, o total da arrecadação.

De acordo com o princípio tributário da capacidade de pagamento, os impostos diretos, em que está classificado o imposto sobre a renda, devem onerar a capacidade potencial que os agentes econômicos têm de auferir renda e/ou elevar o valor do seu patrimônio. A partir do princípio tributário da eqüidade, a base direta de tributação é, teoricamente, perfeita para financiar as políticas públicas de saúde, pois há complementaridade da perspectiva da simetria social. As camadas da população de maior renda ou patrimônio são as que mais sofrem o ônus da tributação. A finalidade da tributação direta é tornar a distribuição da renda equânime. Portanto, a base ideal de tributação é a renda potencial e não a renda corrente dos agentes econômicos. Mas, em qualquer sociedade, é difícil para o Estado mensurar tal potencialidade. Entre outras razões, esta tem sido reivindicada pelo setor público, para a não utilização da base direta de tributação para financiar políticas de assistência à saúde. Assim, o Setor Público pode recorrer a mecanismos engenhosos visando subsidiar a demanda por serviços de atenção à saúde, 
ofertados em condições de bens privados, podendo alcançar, destarte, as metas de distribuição da renda e da arrecadação tributária. Dentre esses mecanismos está o da renúncia fiscal, ou seja, a concessão de benefícios tributários.

No Brasil, estudos sobre o financiamento do setor (Médici, 1990) indicam que, desde os anos 1970, grande parte das famílias é amparada por um terceiro pagador (seguro/plano de saúde ou equivalente) ou desembolsa recursos financeiros próprios para obter acesso aos serviços privados de atenção á saúde. Assim, entende-se que a renúncia fiscal se constitui em forma especial de complementar o financiamento do setor saúde.

\section{CONSIDERAÇÕES FINAIS}

Analisar a renda e os gastos das famílias relacionando-os à renúncia fiscal do setor público no financiamento da atenção privada à saúde é tarefa árdua em função, principalmente, da ausência de informações detalhadas que admitam conclusões abalizadas. No entanto, algumas considerações devem ser feitas.

Houve uma considerável queda do rendimento médio das famílias ao longo da década de 1990 (Pochmann, 2001) e que perdura na atualidade. Desde 1994 o índice de reajuste do salário mínimo tem sido mais vigoroso que os índices que reajustam o salário das outras faixas de renda. ${ }^{8}$ Assim, a renda proveniente dos salários das classes de maior poder aquisitivo tem sofrido um achatamento e são essas classes que estão localizadas no nível superior das alíquotas do imposto de renda. Portanto, são os componentes desse estrato que estão se locupletando dos benefícios tributários. Assim, deduz-se que uma política voltada à redução ou à retirada do subsídio possa não afetar, substancialmente, a demanda por atenção privada, mas implicará, sobremaneira, um maior peso do item saúde para as famílias, já que estão numa curva decrescente de rendimentos, principalmente aquelas acima do limite de isenção (em torno de três salários mínimos atuais ${ }^{9}$ ). É possível deduzir que a demanda se direcionará para uma cesta de consumo focalizada para os itens de imperiosa necessidade e uma migração para prestadores/fornecedores com preços mais competitivos.

No âmbito das empresas é possível supor que o mesmo ocorra, especialmente para aquelas que atuam em mercados competitivos e que não conseguiriam repassar para o preço de seus produtos o gasto com assistência à saúde de seus colaboradores. Percebeu-se, pela análise numérica dos gastos declarados à SRF, que esse tipo de "despesa operacional” vem declinando ano após ano. Só o subsídio fiscal já não tem tanto apelo para a oferta, pelas empresas, desse salário indireto aos seus colaboradores. Esta observação vale também para as empresas em que o

\footnotetext{
${ }^{8}$ Incluindo aposentados e pensionistas do INSS.

${ }^{9}$ A partir de 01/04/2006, o SM será de R \$ 350,00.
} 
fator de produção "trabalho" seja mais significativo, vale dizer, empresas menos intensivas em capital.

Observa-se que a redução ou retirada dos benefícios fiscais oriundos dos gastos privados em saúde implica uma carga adicional para as classes de renda média e para os trabalhadores formais. Não se encontrou indício que a redução ou eliminação da carga tributária redundaria em recursos adicionais para financiar, de modo direto, a população que freqüenta as classes de rendas mais baixas, ou seja, aquelas que estão na área de isenção do imposto de renda. Poder-se-ia argumentar, alternativamente, que haveria a absorção pelo setor público, via SUS, de uma parte da demanda atualmente usuária de serviços privados. Mas o que se tem notado é que esta possível absorção está mais relacionada com uma queda absoluta da renda das famílias e lucro das empresas (excetuando as do setor financeiro) que inviabilizasse o gasto privado, o que teria maior probabilidade de ocorrer para famílias de renda mais baixa e trabalhadores de pequenas e médias empresas.

Outro ponto importante sobre o qual deve haver reflexão é a questão da informação de renda e gastos no mercado da saúde. Há grande esforço da SRF para ajustar as informações que compõem os "benefícios tributários". Evidências empíricas mostram que a eliminação do subsídio implicaria, ainda, uma menor informação sobre a base da receita dos prestadores privados de saúde para finalidades fiscais, cujos efeitos sobre o conjunto da arrecadação de tributos não são, até o momento, quantificáveis.

\section{REFERÊNCIAS BIBLIOGRÁFICAS}

ALMEIDA, C. O Mercado Privado de Serviços de Saúde no Brasil: Panorama Atual e Tendências na Assistência Suplementar. Textos para Discussão n. 599. Brasília, IPEA, 1998.

ANDREAZZI, M. F. S. O Seguro-Saúde Privado no Brasil. Dissertação de Mestrado. ENSP/FIOCRUZ, 1991.

ANDREAZZI, M. F. S. e Kornis G. E. M. Papel das reformas dos anos 90 na demanda por seguros privados de saúde no Brasil — consensos e dissensos. Cad. Saúde Coletiva 2003; 11 (2):201-229.

BIDERMAN, C. \& Arvate, P. Economia do Setor Público no Brasil. Rio de Janeiro, Elsevier Editora, 2005.

DAIN, S. Do Direito Social à Mercadoria. Tese apresentada ao Concurso Público de Títulos e Provas para Professor Titular, na área de Economia e Financiamento do Setor Público, do Departamento de Planejamento e Administração em Saúde do Instituto de Medicina Social da UERJ. Rio de Janeiro, 2000.

IBGE Pesquisa de Orçamentos Familiares 2002-2003. Primeiros Resultados. Rio de Janeiro, 2004. . Pesquisa de Orçamentos Familiares 1995-1996. Rio de Janeiro, 1997.

MÉDICI, A. C. Incentivos Governamentais ao Setor Privado no Brasil. Rio de Janeiro, ENCE/IBGE, Relatórios Técnicos $n^{\circ} 1,1990$.

. O Setor Privado Prestador de Serviços de Saúde no Brasil: Dimensão, Estrutura e Financiamento. Washington, BID, 1990.

. A Crise Econômica e Políticas Sociais: A Questão da Saúde no Brasil. Dissertação de Conclusão de Mestrado em Economia. UNICAMP, 1988.

. A Dinâmica do Setor Saúde no Brasil: As Transformações e Tendências nas Décadas de 80 e

90. Santiago do Chile, Cepal, 1997. 
MINISTÉRIO DA FAZENDA. Consolidação da Declaração do Imposto de Renda das Pessoas Físicas - 2001. Estudos Tributários - 11. Secretaria da Receita Federal Coordenação-Geral de Política Tributária. Brasília, 2002.

. Gastos Governamentais Indiretos, de Natureza Tributária (Gastos Tributários - Conceituação). Estudos Tributários - 12. Secretaria da Receita Federal Coordenação-Geral de Política Tributária. Brasília, 2003

MINISTÉRIO DA SAÚDE. Simpósio Regulamentação dos Planos de Saúde. Brasília, 2001.

OCKÉ R. C. O. O Setor Privado em Saúde no Brasil: os Limites da Autonomia. Dissertação de Mestrado]. Instituto de Medicina Social/UERJ, 1995.

. Os Planos de Saúde no Brasil: Um Estudo Sobre o Mercado, os Gastos e a Regulação. (Tese de Doutorado. Rio de Janeiro, Instituto de Medicina Social - UERJ, 2002.

OCKÉ Reis. C. O. Silveira, F.G. Andreazzi, M. F. S. Avaliação dos Gastos das Famílias com a Assistência Médica No Brasil: O Caso dos Planos de Saúde T.D.N 921. IPEA. Brasília, 2002.

POCHMANN, M. A Década dos Mitos. São Paulo, Ed. Contexto, 2001.

SICSÚ, B. Seguro Saúde No Brasil dos Anos 90: Uma análise da competição empresarial como subsídio ao desenvolvimento da experiência regulatória. Tese de Doutorado. Rio de Janeiro, Instituto de Medicina Social da UERJ, 2002.

SILVEIRA, F.G., Osório, R.G. E Piola, S.F. Os gastos das famílias com saúde. Ciência e Saúde Coletiva;7(4): 719-731 2002.

UGÁ, M. A. D. e SANTOS, I. S. Uma Análise da Equidade do Financiamento do Sistema de Saúde Brasileiro. Relatório de Pesquisa. Projeto Economia da Saúde. Cooperação Técnica Brasil - Reino Unido, 2005. (http://www.opas.org.br/observatorio/arquivos/Destaque99.pdf). 